\title{
In Search for (the Lost) Smartness in Smart Cities: Consumers or Citizens?
}

\author{
Laura Sartori \\ University of Bologna \\ 1.sartori@unibo.it
}

\author{
Davide Arcidiacono \\ University of Catania \\ davide.arcidiacono@gmail.com
}

\begin{abstract}
The paper develops a systematic reflection about the future of smart cites at the time of Covid-19, starting from an original periodization about the evolution of the concept of smartness, declined through a four fold analytical tool (technological, humansocial, institutional and spatial-environmental dimensions). Focusing on the role of smart citizens and on the "right to the city" concept, we list and critically appraise the emerging trends made visible by the worldwide sanitary crisis.
\end{abstract}

\section{Introduction}

This paper aims at developing a systematic but innovative reflection on a long established, but always evolving topic, such as the future of smart cities (SC). We believe it was a needed effort after more than two decades of debates around the concept of smartness declined either as more technological or human - and the more recent and intertwining stream of research on the sharing economy. Yet, today, an urgent and mandatory reflection is needed upon the pandemic's implications we still are discovering. Therefore, we build an original theoretical and methodological framework that will sustain and guide us through the contribution that is divided in two parts: the first offers a periodization of the evolving concept of SC while the second aligns it to those of citizenship and right to the city. Building on the most relevant literature on SC, we aim at updating and positioning the debate while developing an interpretative reading key for we might see in the near future.

The first part will rely on, and also innovate, the tripartite analytical tool developed by Pardo and Nam [1]: to the technological, human and institutional dimensions we add a forth that relates to space and environment, while enlarging the human to a more comprehensive social dimension. We propose a threephase periodization analyzed through the lenses of these 4 dimensions. If for the first two phases we render and propose the debates developed over 25 years based on data analyzed through an original systematic review, for the third phase we list, speculate and critically appraise the emerging trends made visible by the worldwide sanitary crisis. The second part of this contribution builds on the concept of smart citizenship offering an original angle tighten up to the concept of "right to the city". Focusing on the role of citizens for the right to a (smart) city is especially urgent since we suddenly entered a third unplanned, not technologically driven, phase. Our contribution bears 3 points of originality: a novel periodization; the conceptualization of a "smart citizenship"; and the sketch of pressing problems for the "Post-pandemic" Smart City.

\section{The theoretical framework}

The concept of SC evolved and started to be applied as a normative and ideological claim without sufficient conceptual clarification on what it really means. The variety of SC narratives changes according to latitudes [2]: in the global North, the label is therefore adopted to redefine the existing urban infrastructure (often in parallel to a privatization of services and spaces), while in the global South it is used as a political frame for the construction of new cities through an increasingly government led technological urbanization. To set the table for our position paper we need to formulate a specific theoretical framework, building on Pardo and Nam [1] (for the first part), Dahrendorf [3] and Lefebvre [4] (for the second part).

According to Pardo and Nam, understanding the phenomenon of SC, requires a multidimensional scope that looks beyond a technocratic and cyber-enthusiastic vision that matches the citizen centric neoliberal view of SC [5]. The novel approach distinguishes: a technology dimension relating to the implementation of infrastructures (especially ICT) to improve and transform life and work; a human dimension referring to people, education, and knowledge as key drivers for innovation and reconfiguration of existing processes; an institutional dimension calling for specific smart environment's governance and policies to better design 
SC initiatives. However, previous analysis partially overlooked the spatial-environmental dimension that appears increasingly crucial in many definitions. Therefore, the concept of SC makes a strong reference to the theme of sustainability, to the point that its genesis is also traced back to the contents of the Kyoto Protocol in 2005, and highlighted in subsequent documents like the Covenant of Mayors in 2008, where environmental sustainability is the primary objective of the SC [6]. At the same time, architects and urban planners increasingly mix SC design with spatial design and the creation of a "Sustainable User Experience (UX)" or" Green UX" [7]. The major contribution of this approach also lies in the suggestion for a multidisciplinary approach to the SC as a way not to "neutralize" the political dimension [8] inherent to the planning of intelligent urban spaces, shifting away from a neoliberal citizen-centric city that discourages agonistic spaces and active inclusive participation [9]. Building on this, we make a proposal for a novel periodization that accounts for Covid-19 unexpected changes (Section 3).

The second part wants to focus on how the concepts of citizenship and the right to the city could be blended in a smart environment. Here, we rely on the distinction between provisions and entitlements advanced by the German sociologist Ralph Dahrendorf. We argue whether benefiting from a SC citizenship hinges on provisions or entitlements, calling into the field of an unequal structure of (digital) opportunities. In addition, we use Lefebvre's radical concept of "right to the city", formulated to criticize liberal capitalism and its segregating effects on the urban environment. Since its concept does not have a legal but a performative meaning, we unveil possible social conflicts and contradictions within the dominant tech model of governance and management of SC that prevents a full and meaningful participation.

Under this composite framework, we set out some compelling research questions such as: how did the debate on SC evolved over the last 25 years? What are the analytical dimensions that better grasp the turning points of this evolution? What is coming next? How does the concept of citizenship adapt to a smart environment? How does the right to city blend with it?

\section{Methodology}

We adopted a "systematic review method", widely applied in social sciences and public policy evaluation studies [10]. We used different databases for review (Scopus and Web of Science) detecting peer-reviewed articles containing the terms 'smart city/smart cities' in the title from 1990 to 2018 . We restricted the search to the Social Science subject area (SOCI for Web of Science and SSCI Index for Scopus). The examination of the most accredited literature that tried to reconstruct the evolution of the debate on the smart city drove us to choose the presented time periodization. From this initial review, we first collected more than 743 articles, but only 466 articles really fit with the chosen subject area. After the exclusion of duplicates and articles that did not fit to our analysis, a sample of 364 articles was left. We added to this sample also official documents and reports from established institutions (like OECD), reaching 396 items. The T-LAB software allowed an analysis of the content through the co-occurrences of the words used to construct the concept map, clustering each group of words within the renewed theoretical frame of Pardo and Nam. Building on the systematic review and the most renowned contributions, we explore SC phenomenon as a "global discourse network" [11] proposing a novel periodization. Since it is premature to seek established scientific or institutional analysis, our efforts are oriented to offer an innovative interpretative analysis: our reconstruction of possible effects of the pandemic is mostly speculative but grounded on a critical reflection of events and political decisions that took place in the last year. Our goal is to trigger new ideas and analysis for a future research agenda and for innovative policy tools. Therefore, this position paper offers a first interpretative key about how to grasp the transformation and evolution of narratives and policies within the debate on smart cities.

\section{SC through time: from "prodromal" to "post-pandemic"? A proposal for periodization}

Building on the presented approach, we propose a periodization of SC evolution over time that considers four factors at the same time: technological, human, spatial-environmental and institutional. Acknowledging the still fuzzy nature of the concept of $\mathrm{SC}$, and through the literature review, we envision a three stages time period through which it appeared, consolidated, concurred and, then, assimilated other emerging concepts (such as of sharing), and now it is opening to a new formulation. We refer to these 3 steps as "The Prodromal Smart City", "The Sharing City" and the "Post-Pandemic Smart City" (fig.1). 


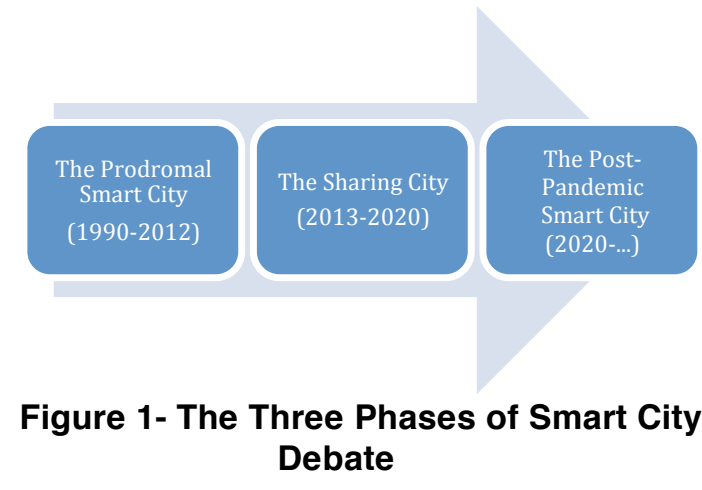

\subsection{The "Prodromal" Smart City}

This first phase is a sort of early Nineties' version of a tech-extractive urban utopia, which mainly feeds on the impulse of the high tech big players who began to building a precise imaginary. As increasingly urban centric, innovation is led by tech entrepreneurs fueled with the Californian ideology [12] that hybridizes participatory ideals, cyber-enthusiasm and economic liberalism.

We can define it as a "prodromal" because it is the stage when the concept of SC begins to take shape, the first experimentations started to be relevant and $41 \%$ of related articles appeared stressing the technological dimensions through urban self-monitoring and selfreporting. It is not surprising the origins of such debate were almost entirely attributable to the marketing strategy of IBM and other tech multinationals that see in the city a new market made of "complex networks of interconnected systems" that monitor and measure urban life, offering policy-makers more complete, reliable and robust data to make the best decisions [13]. IBM came out with a new concept and the "Smart Planet" service package, soon followed by other firms such as CISCO, Siemens and Ericsson. This new package was meant to supply governments with smart solutions focused mainly on transportation, communications, healthcare, energy and utilities. This promotional strategy culminated in the IBM project on the "Smarter Cities Challenge" started in 2010, a program that saw the company's experts providing numerous free consultations to municipal governments around the world. To date, IBM has offered its consultancy services, through the "Smarter Cities Challenge program", to more than 130 cities worldwide, choosing from over 600 applicants. More than 800 IBM experts have offered free consultations and services for an estimated value of $\$ 68$ million.

This technocratic utopia has its symbol in the South of the world: Rio de Janeiro - as our review outlines in 2009 launched the first large-scale SC project as well as the debate of sustainable development. In collaboration with Unicef and the Municipal Secretariat of Health and Civil Defense, this project focuses on the "smart favelas" where teenagers used kites and mobile technology to map the favelas' social and environmental hotspots, taking pictures of potential risks such as piles of rubbish, streets' dangerous spots and hazardous electricity cables. The photos, tagged on a digital map, were used to detect urgency to respond. The project becomes an example of the "thaumaturgical" simplification of the potentiality of SC in an troubled urban environment. Another symbol is the Korean city of Songdo that, in collaboration with Cisco, wanted to become the model for the future of SC in Asia.

The greatest attention is clearly on the technological dimension, focusing on a plurality of enabling technological artifacts understood as "digital infrastructure for communication and knowledge management" embedded in the urban space [14]. Here, the human dimension is understood as a complementary "infrastructure" because SC also needs smart people, their human capital, creativity and participatory orientation. Citizens are "intelligent" agents who use available skills to enjoy and reap off the benefits. Their representation oscillates between being consumers/users of city spaces and services, and being innovative entrepreneurs capable of exploiting the disruptive potential of a new urban paradigm. The human is more instrumental to SC rather than central to it, leading to exemplary failures such as that of Songdo. It became a gated town of expensive housing and international schools, stimulating regional and social imbalances that testify that this top down driven utopia bears troubles in the governance and stakeholder participation.

The spatial-environmental dimension is strictly intertwined to environmental sustainability since it was the primary objective of initial SC's formulations, although a strong technological determinism seriously undermined its originality. Furthermore, not considering the historical-identity dimension of spaces and activities totally underestimated the chances for alternative development paths or ignored embedded specificities within local economies.

The institutional dimensions looks at the role of municipalities that, although amplifier and (financially) promoter of this urban vision, subordinated to the big tech players who provides advice, devices and knowledge in areas where public institutions are largely missing. In this embryonic phase, SC appears as a "commodified" urban space that legitimizes processes of extraction of value centralized in the hands of few private actors who possess adequate skills and technologies. 


\subsection{The "Sharing" City}

The economic crisis of 2008 put this narrative in crisis and critical views on the SC asked for its reconfiguration as also municipalities were looking for more reliable and contingent solutions. In 2013, a cover of the Economist launched the term "sharing economy", or a new digitally mediated peer2peer economy, emerging as a response to the 2007-2008 economic crisis [15]. The narrative hybridizes the SC idea with a new solution, opening up to the second phase, the so-called "Sharing City" (2013-2020). The overlap of the two phenomena holds on some commonalities such as being urban phenomena, driven by connectivity and information technologies, and perceived as improving the quality of urban life through a localized community or active/productive citizenconsumers. Almost one third of the articles about SC contain an explicit reference to the sharing phenomenon. Legitimation and impulse to change perspective are also supported by the emerging promises of a platform economy (experience like Airbnb, BlaBlaCar, Lyft) that grafted into the urban environment. The European Commission has strongly intercepted this idea with the launch of "The Sharing Cities program" that is defined as "a common approach to making smart cities a reality. By fostering international collaboration between industry and cities, the project seeks to develop affordable, integrated, commercial-scale smart city solutions with a high market potential". The Sharing Cities offers also a "framework for citizen engagement and collaboration at local level, thereby strengthening trust between cities and citizens".

Figure 2 compares the "prodromal" concept of SC with its evolution as "sharing city" through an examination of the keywords that emerge from the systematic review, organized along the four dimensions of analysis previously identified. Despite areas of profound complementarity, the two models retain some distinctive connotations.

In the new sharing phase, the technological dimension becomes somehow implicit, focusing more on the relevance of the exchange processes "taking place in ways and on a scale not possible before the internet" [16]. In many cases, the reference to technology is assimilated into the platform conceptualization [17], understood not only as a device but as a new organizational system for innovative smart services.

The human dimension becomes central and no longer instrumental. People represent the "raw material" of the "sharing city". It is no coincidence that the concept of sharing economy derives its strength from explicit references to the gift economy or literature on social networks [18]. The sharing services would be configured as a sui generis category of smart services, in which the human factor is essential and the platforms would appear as amplifiers of community exchanges. People not only own the exchanged assets, but often they are themselves the object of the exchange, as their frame their life inside and outside the platform.

The spatial and environmental factor within the "sharing city" seems strongly related to the previous dimension and somehow interlinked to idea of sharing in itself as the enhancement and efficiency of idle capacities in an exchange system, of "underutilized assets, monetized or not, in ways that improve efficiency, sustainability and community" [19] empowered by digital technologies.

As for the institutional dimension, the increasing relevance of the human and social factors led for developing new governance and regulatory approaches taking into greater account the cultural and social differences of each context. The public actor is somehow empowered, shifting from subordinated to enabler of collaborative networks, trying to reach a series of targets: developing a shared vision on the benefits of sharing among the urban community; promoting "shared" entrepreneurship and collaboration networks between different collaborative service providers; ensuring accessible technologies; engaging dialogue and guidance for the development of solutions and practices that respond to specific needs of the urban community. Areas of intervention can be variously traced in the principles contained in the Shareable Cities Resolution, signed by fifteen major cities of the United States, or in its European counterpart, the European Sharing Economy Coalition (EUROSHE). However, this coordination did not exclude a higher diversification of urban policies and approaches for the "sharing city" [20]: from the San Francisco model, promoting the Sharing Economy Working Group, a multi-stakeholder consultation system on urban policies to the European model, embodied by Amsterdam and Barcelona, centered more on co-designed audits for regulatory solutions that balance the benefits of sharing with the minimization of risks in terms of commodification, gentrification, or social exclusion; to the strongly topdown Seoul model, where the public actor acts not only as a regulator but also as a direct financier of local 


\section{SMART CITY}

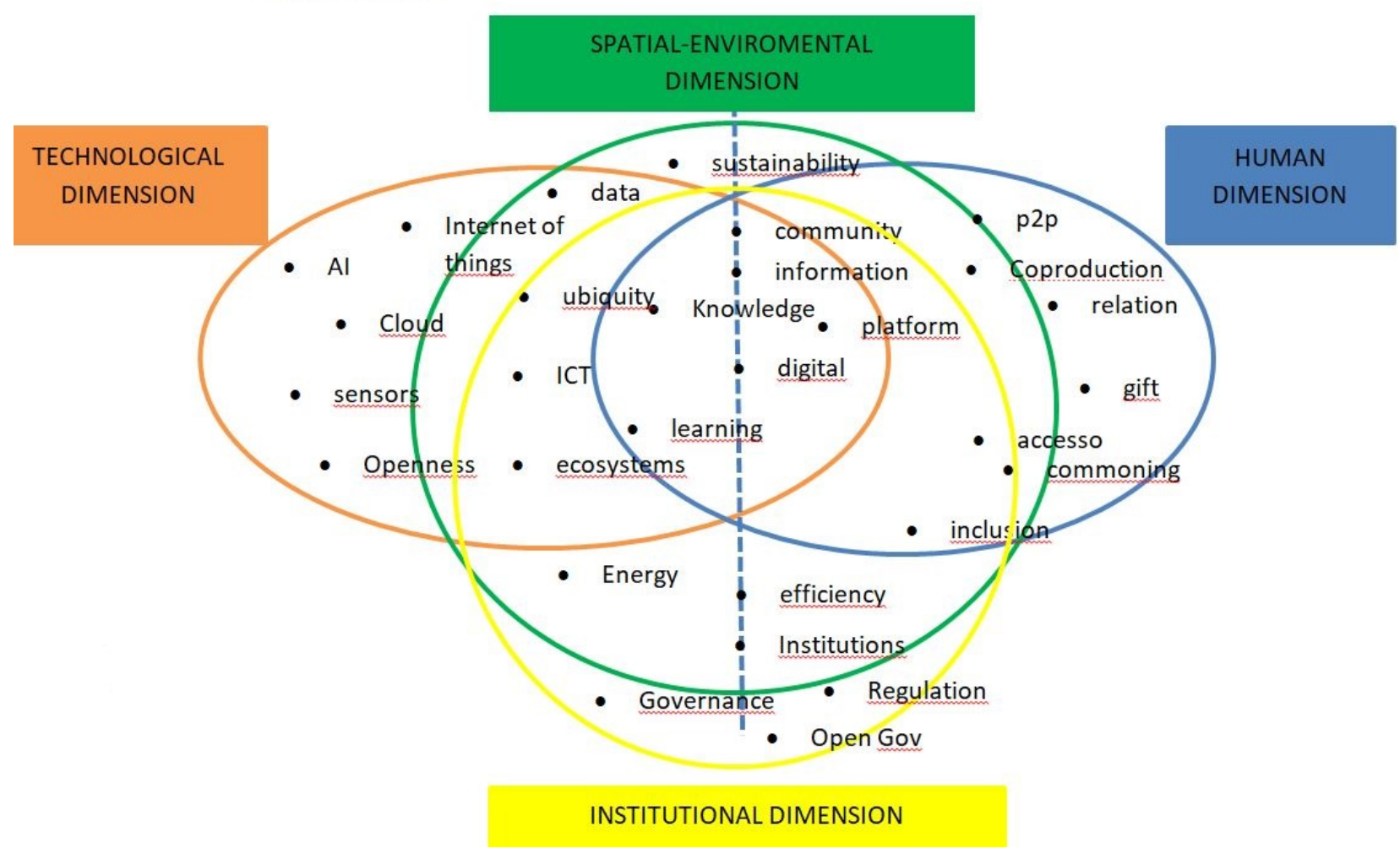

Figure 2 -Comparing the Prodromal Smart City vs the Sharing City

experiences capable of being credible alternatives to the bigger global players. The idea of a "sharing city" as an enhanced human-centric SC, claiming greater social inclusion and collaboration, started to lose its legitimacy as its positive social effects were critically questioned: gentrification effects (Airbnb); exploitation of work (riders and Uber drivers); inequalities in access and use to sharing services, rooted in social exclusion and homophilia of transactional networks (i.e. the case of digital time banks). Risks of value extraction, commodification processes and urban segregation are still evident. Furthermore, the economic sustainability is questioned by the crisis of the most relevant global players of sharing services in terms of return on investments (Car2go and BlaBlaCar), declining trust of investors (WeWork) as well as hard confrontation with public regulators (Airbnb and Uber).

\subsection{The "Post-pandemic" Smart City (2020 - ?)}

The 2020 pandemic sanctions, in our opinion, the end of the "Sharing City" model, decreeing the emergence of a "temporary" model of urban space designed by technology but also new social models: the "Post-pandemic" Smart City. Covid-19 triggered a sudden and stringent reformulation of long-established social processes, whose general consequences are still under investigation (work and family relations; mobility, sociability among many others), definitely in need for specific comprehension when it comes to a smart environment.

Considering the technological dimension, the relevance of the principle of physical distancing calls into question the opportunity of the previous model mainly based on interaction and sociability, while the use of smart and remote working, as a contingent solution, confines sociality back into a domestic dimension, even if strongly mediated by technology. It is an interconnected "empty" city where the technological dimension backlashes once again pivoting towards a stricter focus on the infrastructural networks and their capacity to support the increase in traffic caused by the Covid-19 emergency.

Strengthening the digitalization of public and private services (from delivery, to e-commerce and 
streaming, from electronic medical prescription to digital education or tax electronic payments) becomes a political priority, overcoming long-lasting processes of social and cultural resistance typically embedded in countries with a lower level of digital literacy or digitization (especially Mediterranean and Eastern European countries). Covid-19 forced us to turn to digital services without any significant concern about diversified skills and equipment among social groups and with reduced opt out possibilities, putting the digital divide again back at the center of policy issues. This massive switch to the digital has been accomplished without any regulatory mediation and without considering the emergence of social inequalities.

Human and social dimension flattens on the focus on securitization, which also legitimizes the advent of control and contact tracing tech solutions. The political measures to contain individual freedoms lower the perception of alert with respect to the risk of violation of personal privacy. For example, in Taiwan, municipality used active mobile network monitoring to enforce home quarantine through a twice per day home call to verify that the quarantined have not abandoned their mobile device. Contact tracings apps -like Immuni in Italy or StopCovid in France - are other examples. Surveillance is one of the top issues for citizens: the technical infrastructures allow levels of recording, classification and control that are potentially limitless.

Spatial and environmental dimension. The "Postpandemic Smart City" (see table 1) is an "uninhabited" and vertically hyper-controlled city. However, as nature temporarily re-appropriates the urban space, the collapse of $\mathrm{CO} 2$ in major global cities (from Beijing to Milan) with the decrease in urban mobility highlights how environmental sustainability is not just a question of a more or less technological urban environment but it is heavily dependent on our economic-production model. New studies ascertain a microparticulateCovid-19 strong relationship and propose the urban agenda to maintain a 10 per cent drop in traffic volumes in the recovery phase to significantly improve their climate impact standing [21]. The "Postpandemic" smart city highlights how technology, sustainability and smartness can only be combined with a decrease of mobility and production activities.

Institutional dimension. As for now, there is a revamp of the private-public partnership deemed an effective solution. The public actor (the State rather than the local municipality) negotiates collaboration agreements with companies in a non-transparent way, claiming its vertical power in an open conflict with the decentralized ambitions of the Global Smart Cities. The Chinese Model becomes the new benchmark: apps such as Alipay and WeChat flagged high-risk individuals, who were then quarantined or disallowed from entering public spaces. As normalcy returns, people are required to obtain a "green clearance" from these apps to be allowed back into public life and freely move. Datification of urban policies becomes a priority: in a recent interview Philip James, director of Newcastle Urban Observatory, argued how the Covid19 emergency demonstrated how having real time data in cities is crucial for urban well-being: the provision of hourly data ( 1.8 billion pieces of observational data gathered from 3500 active sensors across the city) proved how restrictions played out on the ground [22]. The "Post-pandemic" SC, despite its transitory model with distinctive characteristics (see table 1), already reveals a series of contradictions and taboos that requires close scrutiny: the infrastructural limits to access and load; the equipment differentiation and technological skills; the lack of awareness about the value of personal data and their economic exploitation; the imperfect compatibility between sustainability and smartness

Table 1. A comparative exercise through the periodization, along the technological (1), human and social (2), spatial-environmental (3) and institutional (4) dimensions

\begin{tabular}{|c|c|c|c|}
\hline & Prodromal Smart City & Sharing City & Post -Pandemic Smart City \\
\hline 1 & $\begin{array}{c}\text { Smart objects and devices } \\
\text { embedded in the urban environment }\end{array}$ & $\begin{array}{c}\text { Sharing Platforms to enable new urban } \\
\text { services }\end{array}$ & $\begin{array}{c}\text { Top transition to } \\
\text { digital and tech surveillance }\end{array}$ \\
\hline 2 & $\begin{array}{c}\text { Consumers or entrepreneurs of } \\
\text { smart services }\end{array}$ & $\begin{array}{c}\text { Collaborative social networks } \\
\text { tech mediated relations }\end{array}$ \\
\hline 3 & Urban Space as a commodity & $\begin{array}{c}\text { Urban Space as an asset or a commons to } \\
\text { share and manage collaboratively }\end{array}$ & $\begin{array}{c}\text { A decongested urban } \\
\text { space environmentally relieved }\end{array}$ \\
\hline 4 & $\begin{array}{c}\text { Smartness as a urban political } \\
\text { vision influenced by big tech players }\end{array}$ & $\begin{array}{c}\text { Municipality as enabler and coordinator of a } \\
\text { sharing environment }\end{array}$ & $\begin{array}{c}\text { Governmental } \\
\text { centralization and Public- } \\
\text { Private-Partnerships for new } \\
\text { data based Tech-solutions }\end{array}$ \\
\hline
\end{tabular}




\section{What role for (smart) citizens?}

Aiming at better qualifying the human dimension as intrinsically social, here we turn our attention to the actual inhabitants of a SC, because - as Shakespeare wrote - "what is the city if not the people?". More generally, here, we want to build up the concept of "smart citizenship" upon the distinction between provisions and entitlements advanced by German sociologist Ralph Dahrendorf [2].

First of all, we should wonder what kind of citizen inhabits a SC enhanced by the ICT revolution, counting that the industrial revolution was a turning point for provisions (of goods) while the French revolution was a watershed for entitlements. In short, provisions are goods and services freely available on the market upon which citizens act their consumption choices while entitlements are individual rights to potentially choose and access those provisions. Their sum reflects the structure of opportunity accessible to individuals and social classes. This is strictly intertwined to the degree of freedom each society allows.

Adapting it to our periodization, the "Prodromal" SC clearly puts an accent on the provisions, the "Sharing City" reformulates and enlarges the variety of provisions available and the "Post-Pandemic" city should eventually focus on the entitlements. As a matter of fact, choosing among an ample selection of goods and services characterizes more a "consumer" rather than a "citizen": changes in the structure and processes of production and delivery through smart technological solutions could apparently democratize consumption opportunities (e.g. costs reduction), but could do nothing in terms of changing an unequal structure of opportunities to access those goods and services. That is to say, the SC does not change the entitlements structure, equivalent to a "ticket entry", to those new provisions. More generally, the overall rhetoric of SC does not solve preexistent inequalities whether we look at access to housing, health and education services. Especially the "prodromal" phase ended up exacerbating what Dahrendorf calls the "Martinez paradox"1: a stark contrast between provisions without entitlements and entitlements without provisions. In our case, only citizens with the "right" (already privileged) entitlements could access

\footnotetext{
1 The anecdote refers to Dahrendorf meeting with Nicaragua's ministry of Commerce in 1986, Alejandro Martinez who defended void stacks at the supermarket: the recent 'revolution' brought along equal opportunities even in the absence of sufficient provisions for all "citizens". The opposite scenario sees plenty of provisions accessible to only a restricted and privileged elite (exemplary of less democratic and equal societies).
}

the new "smart" provisions. It is not surprise how the roadmap to the "smart city utopia" [23] typically started through coalitions of experts, consultants, city officials, and big tech companies, aiming at generating a (vague but) optimistic storytelling about the supposed benefits of SC. In parallel, the roadmap worked to construct an effective representation and bottom-up legitimation, even before a considering the real urban impact. In this discrepancy between vision and practice, especially at the initial stages, the role of citizens is limited to gathering opinions on what this "prototype" should be like. As a matter of fact, citizens have limited capacity and expectations about their involvement to radically influence the project, which is simply aimed at co-opting them for co-production, as shown in a Japanese study on the activation of smart communities [24].

Extending Dahrendorf reasoning and questioning whether the second "Sharing City" phase brought any changes, one could observe that the combination of a sharing economy narrative with the SC rhetoric obfuscated a substantial unmodified equilibrium. Where the focus is on the provision side (as the sharing economy literature teaches us), one may question whether there is a problem in equal opportunities to entitlements.

Within the "sharing city" we find the same vision more oriented to co-production than to smart citizensled processes of deliberation. Although their role is not limited to mere consultancy for service design, it is intensely productive and even exploited. Without an adequate cultural and civic awareness counterweight, the access to sharing services is somehow unequal and their use results in new social conflicts: in several cities like Amsterdam, Paris or Bejing free-floated vehicle sharing systems do not represent an universalistic opportunity for mobility, have a high rate of vandalism and incorrect use (like in the 70s' pre-technological experimentations), damaging both service providers (in terms of economic profitability), municipality (in terms of urban decorum) and users (in terms of efficiency of the service). The pandemic could be a wake-up call for the future of SC: the profound restructuring of economic, social and political processes in both urban and non-urban environments also paves the way to a reformulation of the fuzzy concept under investigation. Nowadays, we have sufficient knowledge for avoiding past errors and really design a SC where citizens are at its core.

To answer the initial question in the light of the structure of opportunities the proposed periodization allows us to qualify the SC inhabitants as "people" rather than "citizens" in both the "Prodromal" and "Sharing" SC. A chance for modifying - or at least not deepening - existing inequalities is to develop a 
framework for a "smart citizenship" - less focused of the consumer who access smart provisions in an unchanged entitlements structure - is to open to the "right to the city" literature.

Lefebvre's radical concept of "right to the city" to criticize liberal capitalism and its segregating effects on the urban environment, is still worthy to orient a progressive smart city policy. It could be declined as a right to act and participate as well as a right to use and accessibility. "The right to the city stresses the need to restructure the power relations that underlie the production of urban space, fundamentally shifting control away from capital and the state and toward urban inhabitants" [25]. The "Prodromal" SC is somehow similar to the urban environment criticized by Lefebvre in 1968: a segregating urban space, even more privatized and commodified, subordinated to private interests to extract and exploit the urban rent, limiting accessibility and right to participate within the urban space. The "Sharing City", despite a brand new imaginary built on collaboration, reproduce the same inequalities both to access and participation within the city: examples are providing car sharing services only in areas of greater profitability and higher demand while applying the extra-tariff system to discouraging their use in peripheral areas or favoring central living spaces to the city user market through short term rentals more than to the housing needs of the inhabitants [26]. The "Post-pandemic" SC does not recognize any citizen's right to the city neither. On the one hand, the smart citizen must be contained, monitored and disciplined in a strongly top down manner, as cases such as that of London's Tube show through constant monitoring and regulation through underground access data. On the other, the great current economic uncertainty questions the profitability of smart city investments. The controversial Toronto Waterfront and Sidewalk Labs project is now definitively stopped but it was scaled down thanks to Block Sidewalk campaign, a legal action launched over citizen rights that produced the privacy advisor to Sidewalk Labs resignation in 2018.

For this reason we think that after the pandemic, the urban imaginary should consider the "right to the city" of its future smart citizen as a viable way to reconcile the four institutional dimensions of the SC paradigm.

\section{Conclusions: how could "smart citizens" really fit in the Post-pandemic SC?}

Since the modern age, social, technological and environmental developments are associated to a national or supranational entity while the last 50 years attribute the driver for innovation and sustainable development on the city. If the city turned from being a danger to be the solution to save the planet [27], one still needs to ponder on advantages and risks that such a change brings about for a SC. Table 2 summarizes and points to potential risks and opportunities in the debate over policies on SC after the pandemic.

Covid-19 paved the way to identifying 'new problems' (such as the changing patterns of mobility, the restructuring of indoor and outdoor spaces such as schools, movie theaters and so on) calling for different urban governance strategies. If this is true, the concept of SC faces a double challenge. First, it should overcome some of its soft points by finding a balance among technological infrastructure solutions, top-down governance policies and the "forgotten" citizen (with its community). A possible triangulation is to be found in a mix of technology, organizational change and participation. Second, by doing so, this solution should fit in a continuously changing and adapting urban vision, independently from Covid-19.

Solving this double challenge would also counteract two previous dangers highlighted when the $\mathrm{SC}$ is seen as the new actor in town for social, economic and environmental development. On the one side, there is a chance not to sell SC solutions as "natural" and "univocal". On the other, the risk of a tech-centered single vision of SC should be substantially contained in the "Post-pandemic" SC compared to the "Prodromal" SC.

Technological dimension. During the pandemic, the translation to smartness (education, training, working, sociality, etc) was fast and reactive, but in the "Postpandemic" SC it should be planned, aware and proactive through a regulatory effort to contain the dominant position of the most important high-tech players. As for now, the market sees a worrying dominance of few big players (GAFAM in Western countries or BATX in Asia) that exercise a control through their oligopolies because, for example, they enjoy the advantage of the first comers thanks to the stickiness and lock-ins of technology.

As Zuboff [28] recently highlighted, capitalism has entered a new phase where is classical capitalistic dynamics (value extraction, market competition, consumer control) moved to ICT technology to fully grasp its potential for surveillance and commodification of the whole human experience. The value extraction imperative exploits the available technology to profit from data collected through smartphones, sensors, CCTV cameras, while transforming them into rents [29]. The triangulation between ubiquitous technology, business search for data and unaware citizen is on the plate to either be contained (if not solved) or exacerbated. 
Table 2. Opportunities and risks in the evolution of the post pandemic SC paradigm

\begin{tabular}{|l|l|l|}
\hline Dimensions & Opportunities & Risks \\
\hline Technological & $\begin{array}{l}\text { Smart transition as a public and political } \\
\text { target }\end{array}$ & $\begin{array}{l}\text { Strengthening tech oligopolies and } \\
\text { infrastructural lock-ins }\end{array}$ \\
\hline Social & Smart citizenship as the core & Deepening social inequalities \\
\hline Spatial-Environmental & $\begin{array}{l}\text { Rethinking mobility and production for a } \\
\text { "real" sustainable transition }\end{array}$ & $\begin{array}{l}\text { The Status quo "resistance": hostility to } \\
\text { radical change in behavior and attitudes }\end{array}$ \\
\hline Institutional & $\begin{array}{l}\text { Deliberative democracy and (urban) open } \\
\text { government data }\end{array}$ & Political surveillance \\
\hline
\end{tabular}

Human and social dimension. Main challenges are related to exacerbating existing inequalities coupled with a consumer/people vision of SC. Seeing people as an "infrastructure", although relevant, does miss the point of transforming people/consumers into citizens. As it took time for other civil and social "rights" to consolidate, it will take its journey to develop a "smart citizenship". A concrete peril is to continue with a biased "smart" urbanism and datadriven governance that heavily affect and automate inequalities [30] [31], eroding citizens' invisibility and privacy [32]. More specifically, a "Post-pandemic" city will not only rely on technology and "smart" urbanism but also on social policies intervening in rebalancing those entitlements and making access to SC more equal.

The focus on smart citizenship must become the heart of the "Post-pandemic" SC design. Recovering the lost "ethos" in the decline of the "Sharing city", requires considerable efforts in the promotion of the ability to enhance the smart citizen's agency, not only as a consumer, co-producer or as service enabler, but also as a policy "hub" for urban planning. To do this we must start from citizenry, understood as the ability to exercise one's "right to the city", working on tools and skills, but also on the social awareness of roles and commitments within the city. The public value of citizen data and the limitations to their use, such us the capability to develop a collective dimension of citizen voice [33] in the urban environment are core issues of this process as a way to guarantee both the "right of access" and "the right to participate". Ratti and Claudel [34] propose a collaborative futurecraft in which deliberation, accessibility to knowledge and information, and co-production create the most fertile and useful ecosystem for a real smart city.

Spatial-environmental dimension. The main challenges here are related to the interference between public and private space. The "onlife" way of living [35] could also represent the blurring between the top down (such as in the "postpandemic" SC) and the prosumer orientations for digitally centralized proactive urban governance.

Smart citizens need more deliberative and collective tools, taking strength also by the new global and urban movements such as "Occupy", "Fridays for the future" or "Platform-cooperativism movement" that were already praising for this kind of change. Their contribution is also crucial for a true green transition, capable to question and challenge existing production models and imagine new ones (e.g. through the rediscovery of peri-urban agriculture, the organization of energy community cooperatives, the long and short distance carpooling models). The SC must be the ideal space for this concrete "social" innovation because it is rich in economic, cultural and social capital that can fuel this experimentation.

Institutional dimensions. Main challenges relate to the role the public could embody. What role and vision should the public have? Why it should develop it? Not only a facilitator for bottom-up processes that are way to difficult to manage and sustain than just giving out money for "smart" initiatives. Its role should be propulsive, regulatory while empowering. On a continuum we have two opposite ideal cases: the first scenario sees government in active coordination with citizens to co-design smart initiatives for the public good while the second scenario sees the government manipulatively profit from potential for control. The USA and the EU have their differences but they project thoughtful and more cautious experiments while China is more audacious in launching a "social credit system", heavily organized around control and surveillance. Around the world, the idea of smartness (and SC) is becoming an applied field for social control under the shield of surveillance offered by the technical infrastructure becoming more and more normalized and, thus, socially accepted. Covid-19 has 
dramatically shown how under emergency circumstances the process of normalization spikes.

We conclude by highlighting how difficult and critical is to develop a framework that really serves citizen empowerment. Previous SC schemes did not quite serve the purpose as they were only built around the magic bullet of "technology". Technology could be effectively connected to citizens (and vice versa) without curtailing their rights and entitlements. Future schemes could benefit from a more diversified stream of research, going from technology to innovation, citizenship rights, co-created and codesigned policy. There is a need for a shifting away from the "smart" city to the "smart" people, from smart urbanism to "sustainable urbanism for smart citizen(ship)".

\section{References}

[1] T.A. Pardo, T. Nam, "Conceptualizing Smart City with Dimensions of Technology, People, and Institutions", Proceedings of the 12th Annual International Conference on Digital Government Research, College Park, Maryland, USA - June 12 - 15, 2, 2011, pp. 282-292.

[2] A. Greenfield, Against the Smart City. Verso, NY, 2013.

[3] R. Dahrendorf, The Modern Social Conflict. An Essay on the Politics of Liberty, Springer, New York, 1988.

[4] H. Lefebvre, Le droit à la ville. Anthopos, Paris, 1968. [5] P. Cardullo, R. Kitchin, Smart urbanism and smart citizenship: The neoliberal logic of 'citizen-focused' smart cities in Europe", EPC: Politics and Space, 37(5), 2019, 813-830.

[6] D. Arcidiacono, "Dalla Smart City alla Sharing City: Verso un nuovo ecosistema urbano?", Sociologia Urbana e Rurale" 122, 2020, pp. 77-95.

[7] A. Pollini, "Users' Practices and Software Qualities: a Dialectical Stance, International Workshop on the Interplay between Usability Evaluation and Software Development", (I-USED 2008), Pisa, Italy, September 24th, 2008, pp. 1-7.

[8] N. Brenner and C. Schmid (2015) Towards a new epistemology of the urban?, City, 19:2-3, 151-182.

[9] C. Mouffe Deliberative Democracy or Agonistic Pluralism?, Social Research, 66, 745-758.

[10] M. Petticrew, H. Roberts, Systematic Reviews in the Social Sciences, Blackwell, Oxford, 2006.

[11] S. Joss, F. Sengers, D. Schraven, F. Caprotti \& Y. Dayot "The Smart City as Global Discourse: Storylines and Critical Junctures across 27 Cities", Journal of Urban Technology, 26:1, 2019, pp. 3-34.

[12] R. Barbrook, A. Cameron, "The Californian Ideology". Science as a Culture, 6 (1), 1996, pp. 44-72.

[13] L. Sartori, "Alla ricerca della smart citizenship". Le istituzioni del Federalismo, 4, 2015, pp. 927-948.

[14] N. Komninos, "The Architecture of Intelligent Cities. Intelligent Environments", Institution of Engineering and Technology, 6, 2006, pp. 13-20.

[15] J. Schor, Debating Sharing Economy, Great Transition Initiative, 2014, http://www.greattransition.org/
[16] R. Botsman, Defining The Sharing Economy: What Is Collaborative Consumption And What Isn't? FastCompany, 2015.

[17] M. Kenney, J. Zysman J., "The Rise of the Platform Economy", Science and Technology, 32(3), 2016.

[18] I. Pais, G. Provasi, " Sharing economy: a step towards 're-embedding' the economy?", Stato e Mercato, 105(3), 2015, pp. 347-377.

[19] A. Rinne, "What Exactly is the Sharing Economy?", World Economic Forum, 13 December, 2017.

[20] I. Pais, S. Mazzucotelli, Sharing Economy as an Urban Phenomenon: Examining Policies for Sharing Cities, in Meil P., Kirov V., eds., Policy Implications of Virtual Work, Palgrave, London, 2017.

[21] SmartCitiesWorld, Can US cities preserve some of their pandemic environmental gains?, https://www.smartcitiesworld.net/news/can-us-citiespreserve-some-of-their-pandemic-environmental-gains$\underline{5361}$

[22] D. Leprince-Ringuet, Smart cities will track our every move, https://www.zdnet.com/article/smart-cities-will-track-our-everymove-we-will-need-to-keep-them-in-check/

[23] AM. Valdez, M. Cook, S. Potter, "Roadmaps to Utopia: Tales of the Smart City”, Urban Studies, 2020, 1, pp. 1-20.

[24] B. Granier, H. Kydo, "How are Citizens Involved in Smart Cities? Analysing Citizen Participation in Japanese 'Smart Communities"'. Information Polity, (21)1, 2016, pp. 61-76.

[25] M. Purcell, "Excavating Lefebvre: The Right to the City and its Urban Politics of the Inhabitant", GeoJournal, 58, 2002, pp. 99-108.

[26] D. Arcidiacono, M. Duggan, Sharing Mobilities. Questioning our Right to the City in the Collaborative Economy, Routledge, London, 2020.

[27] H. Angelo," "Why Does Everyone Think Cities can Save the Planet?”, Urban Studies, 2020, pp. 1-21.

[28] S. Zuboff, The Age of Surveillance Capitalism. The Fight for a Human Future and the New Frontier of Power, Public Affairs, New York, 2019.

[29] J. Sadowski, "The Internet of Landlords: Digital Platforms and New Mechanisms of Rentier Capitalism". Antipode 52(2), 2020, pp. 562-580.

[30] D. Curran, A. Smart, "Data-driven governance, smart urbanism and risk-class inequalities: Security and social credit in China", Urban Studies, 2020, Online first.

[31] V. Eubanks, Automating Inequality: How High-Tech Tools Profile, Police, and Punish the Poor, St. Martin's Press, New York, 2017.

[32] R. Kitchin, "The Real-time City? Big Data and Smart Urbanism", GeoJournal 79(1), 2014, pp. 1-14.

[33] FEEM, Which future for the cities after covid-19. Aninternational survey, 2020, https://www.feem.it/m/news/executive-summary-citiescovid191.pdf

[34] C. Ratti, M. Claudel, The City of Tomorrow: Sensors, Networks, Hackers, and the Future of Urban Life, Yale University Press, London, 2016.

[35] L. Floridi, The Onlife Manifesto: Being Human in a Hyperconnected Era, Springer, London, 2014. 